\title{
A design of solar battery cleaning system by modularity method
}

\author{
L.K. Dien ${ }^{1, *}$, and Svetlin Antonov ${ }^{2}$ \\ ${ }^{1}$ Saigon Technology University (STU), Faculty of Mechanical Engineering, Vietnam \\ ${ }^{2}$ Technical university of Sofia, Faculty of telecommunications, Bulgaria
}

\begin{abstract}
According to the World Bank statistical report, Vietnam has an average of 1,600-2,700 hours of sunshine and normal direct radiation averaging $4-5 \mathrm{kWh}$ per square meter a day. Before 2017 , solar energy was considered worthless in Vietnam's energy development strategy, but by the end of 2019, Vietnam overtook Malaysia and Thailand to become the country with the largest solar panel installation capacity in Southeast Asia. The photovoltaic projects in Vietnam has reached 5 gigawatts (GW), far exceeding from the target of $1 \mathrm{GW}$ that proposed by the Government in 2020 [1]. The strong development of solar energy from industry to civil activities has led to the development of ancillary services such as installation, maintenance and commerce. To ensure the productivity, all solar panels must be cleaned to absorb solar energy as much as possible. In the paper, we mention on the design of a solar panel cleaning robot that has a compact size, easy to move through the panels, taking advantage of domestic factors to have an edge price. The highlight point in that work is our application of the modularity method to gain the best competition with the other existing products on the market.
\end{abstract}

\section{Introduction}

The application of modularity method for design of mechanical products has developed rapidly in recent years [1]. At present, it has become a perfect and effective method that can help the design to overcome so many proposed conditions such as: low price, high productivity, interchangeability ... $[2,3]$. Due to the trend of the diversification of customers' demands, small product batches with high varieties, the modular design has been applied widely [4] in this paper.

From the above demands, the application of modular design of the mechanical systems is indispensable. The objective of the modularization design in the article is the solar panel cleaning system or solar panel cleaning robot $[5,6]$ that could gain the following competitive points: compact size, effective working on effective clean panel surfaces, easy to activate, and lowest price by taking advantage of domestic factors.

\footnotetext{
* Corresponding author: dien.lekhanh@,stu.edu.vn
} 


\section{Method of design process}

Application of the functional analysis [7] for solar battery cleaning system, from the above complete general demands, we divided the sub-functions as in the Fig. 1.

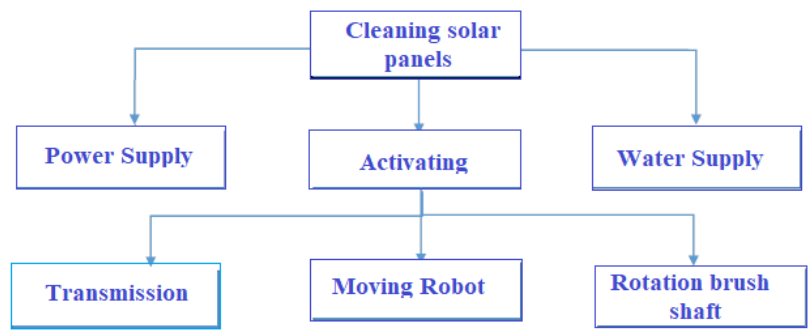

Fig. 1. Functional schema of solar battery cleaning system.

Proposing ideas for the design problem [7]: Deploy ideas for each function, systematically combine ideas, we get 4 ideas for the design of cleaning solar panels as in Table 1.

Table 1. Implementation ideas for each function.

\begin{tabular}{|c|c|c|c|c|}
\hline Function & Idea 1 & Idea 2 & Idea 3 & Idea 4 \\
\hline $\begin{array}{c}\text { Power } \\
\text { supply }\end{array}$ & $\begin{array}{c}\text { Power supply from } \\
\text { solar panels }\end{array}$ & $\begin{array}{c}\text { Power supply } \\
\text { from outside } \\
\text { source }\end{array}$ & $\begin{array}{c}\text { Power supply } \\
\text { from solar panels }\end{array}$ & $\begin{array}{c}\text { Power supply } \\
\text { from outside } \\
\text { source }\end{array}$ \\
\hline $\begin{array}{c}\text { Water } \\
\text { Supply }\end{array}$ & Pump & Pump & Pump & Pump \\
\hline Transmission & $\begin{array}{c}\text { Transmission by } \\
\text { coupling and gears }\end{array}$ & $\begin{array}{c}\text { Transmission by } \\
\text { coupling and belt }\end{array}$ & $\begin{array}{c}\text { Transmission by } \\
\text { gearbox and belt }\end{array}$ & $\begin{array}{c}\text { Transmission by } \\
\text { coupling and gears }\end{array}$ \\
\hline $\begin{array}{c}\text { Rotation } \\
\text { Brush Shaft }\end{array}$ & Motor & Belt & Belt & Motor \\
\hline $\begin{array}{c}\text { Moving } \\
\text { robot }\end{array}$ & Servo motor DC & Servo motor DC & Servo motor DC & Servo motor DC \\
\hline
\end{tabular}

Preliminary concept evaluation for designed product [7]: The ideas are listed on the first horizontal row of the selection matrix. The selection criteria are arranged along the left column of the matrix. Choose one of the above ideas as a base. Analysis of each idea: ideas are compared with base one according to the selection criteria and scored in the corresponding box (Table 2). From the above ideas we consider that the ideas 1 and 3 are feasible when design the robot.

Calculating the ideal scores for the final product design [7]: Decision matrix with additional weight column. Selection criteria are assigned a weight (in percentage), which are determined by consensus of the design team. Analysing each idea: the ideas are compared with the standard idea according to the selection criteria and scored in the corresponding box. Calculate the total score of each idea by the formula:

$$
S_{j}=\sum_{i=1}^{n} r_{i j} w_{i}
$$


where: $r_{i j}$ - the first criterion point of idea $\mathrm{j} ; w_{i}$-the weight of the $\mathrm{i}^{\text {-th }}$ criterion; $n$-total number of criteria; $S_{j}$ - total score for idea $j$.

Rank the ideas by total score are showed in Table 3.

Table 2. Matrix of evaluation the ideas.

\begin{tabular}{|c|c|c|c|c|}
\hline \multirow{2}{*}{ Criteria } & \multicolumn{4}{|c|}{ Ideas } \\
\cline { 2 - 5 } & 1(selected as base) & 2 & 3 & 4 \\
\hline Logical productivity & + & 0 & 0 & + \\
\hline Effective hygiene & + & 0 & 0 & + \\
\hline Facility to activate & - & + & + & - \\
\hline Saving resources & 0 & 0 & 0 & - \\
\hline High longivity, high reability & + & 0 & + & + \\
\hline Ease to mantenance & + & 0 & + & + \\
\hline Applicable remote control technology & + & + & + & + \\
\hline Logical price & 0 & + & + & - \\
\hline Use recyclable materials & + & + & + & + \\
\hline Total marks (+) & 6 & 4 & 6 & 6 \\
\hline Total marks (0) & 3 & 5 & 3 & 0 \\
\hline Total marks (-) & 1 & 0 & 0 & 3 \\
\hline Ultimate total marks & 5 & 4 & 6 & 3 \\
\hline Range & 2 & 3 & 1 & 4 \\
\hline Continue or stop & Yes & No & Yes & No \\
\hline
\end{tabular}

Table 3. Matrix of scoring and selection of ideas.

\begin{tabular}{|c|c|c|c|c|c|}
\hline \multirow{4}{*}{ Criteria } & \multirow{4}{*}{ Weights(\%) } & \multicolumn{4}{|c|}{ Ideas } \\
\hline & & \multirow{2}{*}{\multicolumn{2}{|c|}{$\frac{3}{\text { Marks }}$}} & \multirow{2}{*}{\multicolumn{2}{|c|}{\begin{tabular}{|l}
4 \\
Marks
\end{tabular}}} \\
\hline & & & & & \\
\hline & & Coarse & $\begin{array}{c}\text { Multipled } \\
\text { to weight }\end{array}$ & Coarse & \begin{tabular}{|c|} 
Multipled \\
to weight \\
\end{tabular} \\
\hline Hygenic effect & $10 \%$ & 4 & 0.4 & 3 & 0.3 \\
\hline Easy to activate & $6 \%$ & 2 & 0.12 & 4 & 0.24 \\
\hline Resource saving & $15 \%$ & 3 & 0.45 & 3 & 0.45 \\
\hline High longivity, high reability & $16 \%$ & 3 & 0.48 & 5 & 0.8 \\
\hline Easy maintenance & $10 \%$ & 4 & 0.4 & 5 & 0.5 \\
\hline $\begin{array}{l}\text { Application of remote control } \\
\text { technology }\end{array}$ & $6 \%$ & 3 & 0.18 & 3 & 0.18 \\
\hline Logical price & $22 \%$ & 3 & 0.66 & 4 & 0.88 \\
\hline Use recyclable materials & $5 \%$ & 3 & 0.15 & 3 & 0.15 \\
\hline Total marks & 100 & \multicolumn{2}{|c|}{3.24} & \multicolumn{2}{|r|}{3.8} \\
\hline \multicolumn{2}{|l|}{ Ranking } & \multicolumn{2}{|r|}{2} & \multicolumn{2}{|r|}{1} \\
\hline \multicolumn{2}{|l|}{ Continues? } & \multicolumn{2}{|c|}{ No } & \multicolumn{2}{|c|}{ Yes } \\
\hline
\end{tabular}

Based on the scoring matrix, the design team chooses an idea as a design concept. Solar battery cleaning system principle diagram as follows: 


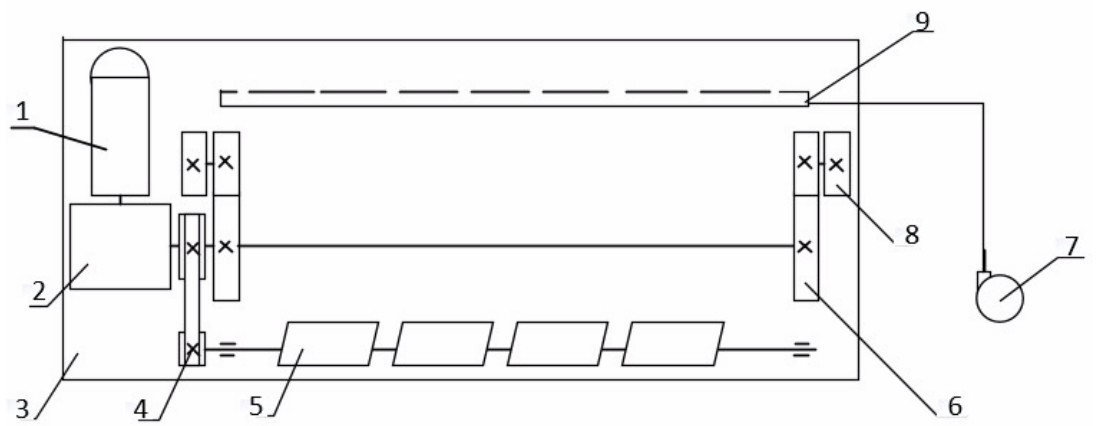

Fig. 2. Theoretical schemas of solar battery cleaning system: 1- servo motor; 2- gear box; 3- machine frame; 4- belt conveyor; 5- brush shaft; 6- Gear; 7- pressure pump; 8- wheels; 9- water pipes.

\section{Results and discussion}

After application of the design product modularization method [8] to design the system after analysing the demands of customer and choosing a design concept for the product, we combine the functional analysis diagrams and the design concepts in one structural functional diagram that is illustrated in the following diagram:

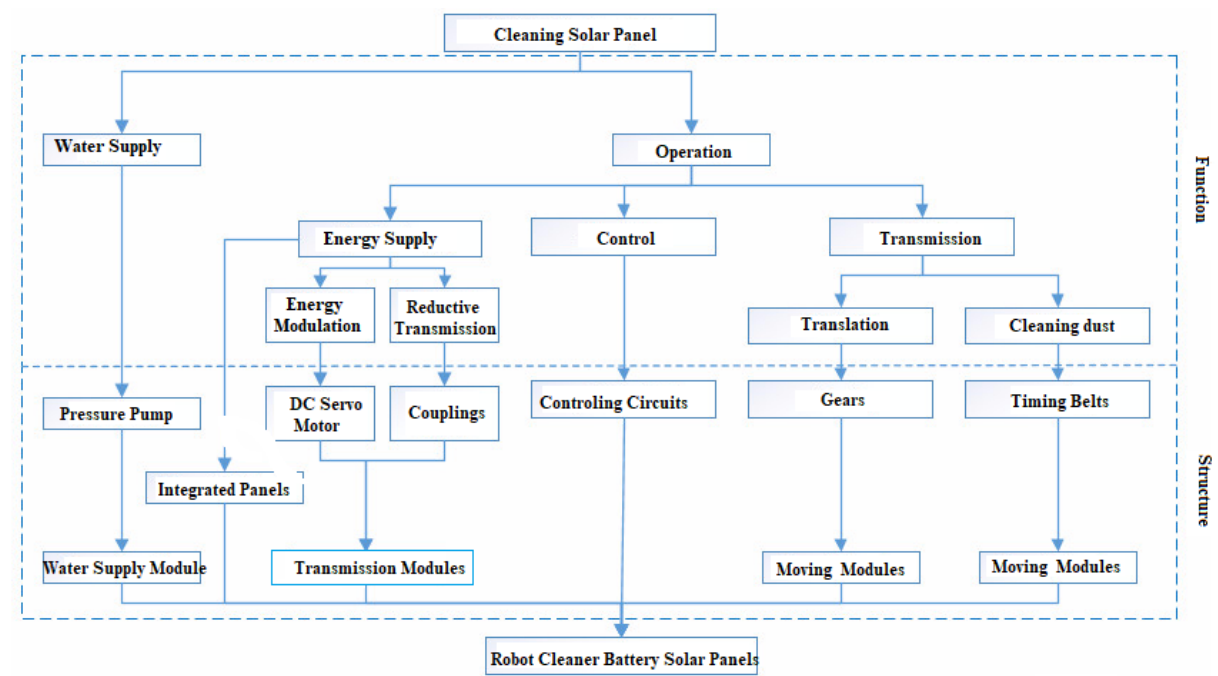

Fig. 3. Schema of structure and function of solar battery cleaning system

List of the components and symbols is shown in Table 4: 
Table 4. Parts designation solar battery cleaning system.

\begin{tabular}{|l|l|l|}
\hline & Components & Designation \\
\hline 1 & Servo DC motor & DDC \\
\hline 2 & Flexible coupling & NTD \\
\hline 3 & Reductive gearbox & HGT \\
\hline 4 & Gear & BR \\
\hline 5 & Belt transmission & BTD \\
\hline 6 & Wheel & BX \\
\hline 7 & Brush shaft & TC \\
\hline 8 & Pressure pump & BAS \\
\hline 9 & System of water tube & HTN \\
\hline
\end{tabular}

The system-level specifications of the product are orderly sorted in a hierarchical structure in where the physical structure is divided according to the arrangement and the interactive state (direct or indirect), while the functional structure is divided according to the flow of energy, materials and information as in Figure 4.

Establishing the relationships of the details in the system [8] through the properties of physical structure and function of the system (Table 5), number 1 represents interaction, 0 represents no relationship system; NT- serial; SS- parallel; TT- direct interaction; GTindirect interaction.

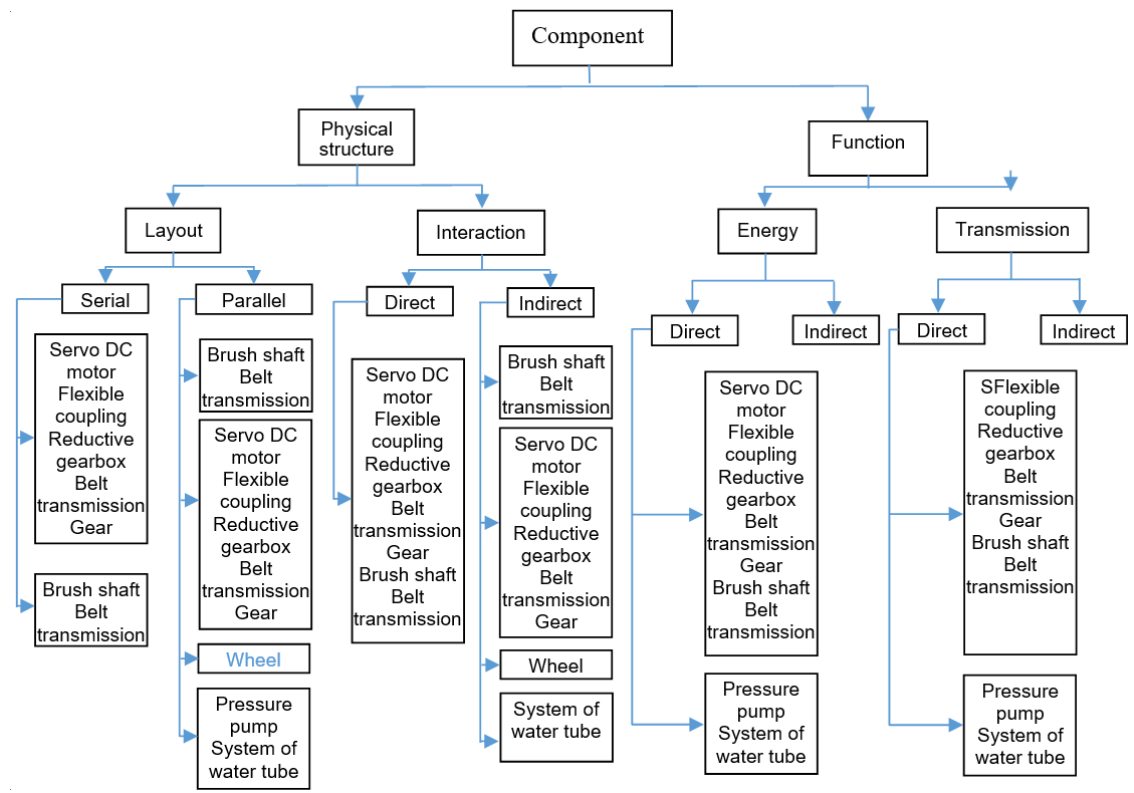

Fig. 4. Schema of structure and function of solar battery cleaning system 
Table 5. The relationships of the details in the system.

\begin{tabular}{|c|c|c|c|c|c|c|c|c|c|}
\hline \multirow{3}{*}{\multicolumn{2}{|c|}{$\begin{array}{l}\text { Mechanical details/ } \\
\text { Cluster of details }\end{array}$}} & \multicolumn{4}{|c|}{ Structure } & \multicolumn{4}{|c|}{ Function } \\
\hline & & \multicolumn{2}{|c|}{ Arrangement } & \multicolumn{2}{|c|}{ Interaction } & \multicolumn{2}{|c|}{ Energy } & \multicolumn{2}{|c|}{ Transmission } \\
\hline & & $N T$ & $S S$ & $T T$ & $G T$ & $T T$ & $G T$ & $T T$ & $G T$ \\
\hline \multirow{8}{*}{$D D C$} & NTD & 1 & 0 & 1 & 0 & 1 & 0 & 1 & \begin{tabular}{|l|}
0 \\
0
\end{tabular} \\
\hline & $H G T$ & 1 & 0 & 0 & 1 & 0 & 1 & 0 & 1 \\
\hline & $B R$ & 1 & 0 & 0 & 1 & 0 & 1 & 0 & 1 \\
\hline & $B T D$ & 1 & 1 & 0 & 1 & 0 & 1 & 0 & 1 \\
\hline & $B X$ & 0 & 1 & 0 & 1 & 0 & 1 & 0 & 1 \\
\hline & $T C$ & 0 & 0 & 0 & 1 & 0 & 1 & 0 & 1 \\
\hline & $B A S$ & 0 & 0 & 0 & 0 & 0 & 0 & 0 & 0 \\
\hline & $H T N$ & 0 & 0 & 0 & 0 & 0 & 0 & 0 & 0 \\
\hline \multirow{7}{*}{$N T D$} & $H G T$ & 1 & 0 & 1 & 0 & 1 & 0 & 1 & 0 \\
\hline & $B R$ & 0 & 1 & 0 & 1 & 0 & 1 & 0 & 1 \\
\hline & $B T D$ & 0 & 1 & 0 & 1 & 0 & 1 & 0 & 1 \\
\hline & $B X$ & 0 & 0 & 0 & 1 & 0 & 1 & 0 & 1 \\
\hline & $T C$ & 0 & 0 & 0 & 1 & 0 & 1 & 0 & 1 \\
\hline & $B A S$ & 0 & 0 & 0 & 0 & 0 & 0 & 0 & 0 \\
\hline & HTN & 0 & 0 & 0 & 0 & 0 & 0 & 0 & 0 \\
\hline \multirow{6}{*}{$H G T$} & $B R$ & 1 & 0 & 1 & 0 & 1 & 0 & 1 & 0 \\
\hline & $B T D$ & 1 & 0 & 1 & 0 & 1 & 0 & 1 & 0 \\
\hline & $B X$ & 0 & 1 & 0 & 1 & 0 & 1 & 0 & 1 \\
\hline & \begin{tabular}{|l}
$T C$ \\
$T C$
\end{tabular} & 0 & \begin{tabular}{|l} 
\\
\end{tabular} & 0 & 1 & 0 & 1 & 0 & $\begin{array}{l}1 \\
\end{array}$ \\
\hline & $B A S$ & 0 & 0 & 0 & 0 & 0 & 0 & 0 & 0 \\
\hline & HTN & 0 & 0 & 0 & 0 & 0 & 0 & 0 & 0 \\
\hline \multirow{5}{*}{$B R$} & $B T D$ & 0 & 0 & 0 & 0 & 0 & 0 & 0 & 0 \\
\hline & $B X$ & 1 & 0 & 1 & 0 & 1 & 0 & 1 & 0 \\
\hline & $T C$ & 0 & 0 & 0 & 0 & 0 & 0 & 0 & 0 \\
\hline & $B A S$ & 0 & 0 & 0 & 0 & 0 & 0 & 0 & 0 \\
\hline & $H T N$ & 0 & 0 & 0 & 0 & 0 & 0 & 0 & 0 \\
\hline \multirow{4}{*}{$B T D$} & $B X$ & 0 & 0 & 0 & 0 & 0 & 0 & 0 & 0 \\
\hline & \begin{tabular}{|l}
$T C$ \\
\end{tabular} & 1 & 0 & 1 & 0 & 1 & 0 & 1 & 0 \\
\hline & $B A S$ & 0 & 0 & 0 & 0 & 0 & 0 & 0 & 0 \\
\hline & $H T N$ & 0 & 0 & 0 & 0 & 0 & 0 & 0 & 0 \\
\hline \multirow{3}{*}{$B X$} & $T C$ & 0 & 0 & 0 & 0 & 0 & 0 & 0 & 0 \\
\hline & $B A S$ & 0 & 0 & 0 & 0 & 0 & 0 & 0 & 0 \\
\hline & HTN & 0 & 0 & 0 & 0 & 0 & 0 & 0 & 0 \\
\hline \multirow{2}{*}{$T C$} & $B A S$ & 0 & 0 & 0 & 0 & 0 & 0 & 0 & 0 \\
\hline & $H T N$ & 0 & 0 & 0 & 0 & 0 & 0 & 0 & 0 \\
\hline$B A S$ & PTB & 1 & 0 & 1 & 0 & 1 & 0 & 1 & 0 \\
\hline
\end{tabular}

Determining the influence of System - Level Specification (SLS) on General Functional Requirements (GFR) [8]:

To determine the effect of the properties of machine on the functional requirements, we use a relationship matrix between machine design requirements and importance factors value:

1: the desired impact value;

0 : the insignificant impact value;

-1 : the undesirable effect value.

Then we build a matrix of relationships between Systems - Level Specification on General Functional Requirements (Table 6). 
Table 6. Relationship matrix between SLS and GFR.

\begin{tabular}{|l|c|c|c|}
\hline & \multicolumn{3}{|c|}{ General Functional Requirements (GFR) } \\
\hline System - Level Specifications (SLS) & Ease of Service & Compactness & Performance \\
\hline Serial arrangement & 1 & 1 & 0 \\
\hline Parallel arrangement & 0 & 1 & 1 \\
\hline Direct interaction & 1 & 1 & 1 \\
\hline Indirect interaction & 0 & 0 & 0 \\
\hline Direct Energy & 1 & 1 & 0 \\
\hline Indirect Energy & 1 & 0 & 1 \\
\hline Direct transmission & 1 & 1 & 0 \\
\hline Indirect transmission & 1 & 0 & 1 \\
\hline Weight & 1 & 1 & 1 \\
\hline
\end{tabular}

Applying Cluster Identification Algorithm (CIA) [8], we can determine the matrix of functional (Table 7), structural (Table 8) and overall similarity (Table 9).

Table 7. The structural similarity matrix.

\begin{tabular}{|l|l|l|l|l|l|l|l|l|l|}
\hline & DDC & NTD & HGT & BR & BTD & BX & TC & BAS & HTN \\
\hline DDC & & 5 & 2 & 2 & 2 & 2 & 2 & 0 & 0 \\
\hline NTD & 5 & & 5 & 2 & 2 & 0 & 0 & 0 & 0 \\
\hline HGT & 2 & 5 & & 5 & 5 & 2 & 2 & 0 & 0 \\
\hline BR & 2 & 2 & 5 & & 0 & 5 & 0 & 0 & 0 \\
\hline BTD & 2 & 2 & 5 & 0 & & 0 & 5 & 0 & 0 \\
\hline BX & 2 & 0 & 2 & 5 & 0 & & 0 & 0 & 0 \\
\hline TC & 2 & 0 & 2 & 0 & 5 & 0 & & 0 & 0 \\
\hline BAS & 0 & 0 & 0 & 0 & 0 & 0 & 0 & & 5 \\
\hline HTN & 0 & 0 & 0 & 0 & 0 & 0 & 0 & 5 & \\
\hline
\end{tabular}

Table 8. The functional similarity matrix.

\begin{tabular}{|l|l|l|l|l|l|l|l|l|l|l|}
\hline & DDC & NTD & HGT & BR & BTD & BX & TC & BAS & HTN \\
\hline DDC & & 4 & 4 & 4 & 4 & 4 & 4 & 0 & 0 \\
\hline NTD & 4 & & 4 & 4 & 4 & 4 & 4 & 0 & 0 \\
\hline HGT & 4 & 4 & & 4 & 4 & 4 & 4 & 0 & 0 \\
\hline BR & 4 & 4 & 4 & & 0 & 4 & 4 & 0 & 0 \\
\hline BTD & 4 & 4 & 4 & 0 & & 0 & 4 & 0 & 0 \\
\hline BX & 4 & 4 & 4 & 4 & 0 & & 0 & 0 & 0 \\
\hline TC & 4 & 4 & 4 & 4 & 4 & 0 & & 0 & 0 \\
\hline BAS & 0 & 0 & 0 & 0 & 0 & 0 & 0 & & 4 \\
\hline HTN & 0 & 0 & 0 & 0 & 0 & 0 & 0 & 4 & \\
\hline
\end{tabular}

Table 9. The general similarity matrix.

\begin{tabular}{|l|l|l|l|l|l|l|l|l|l|}
\hline & DDC & NTD & HGT & BR & BTD & BX & TC & BAS & HTN \\
\hline DDC & & 9 & 6 & 6 & 6 & 6 & 6 & 0 & 0 \\
\hline NTD & 9 & & 9 & 6 & 6 & 4 & 4 & 0 & 0 \\
\hline HGT & 6 & 9 & & 9 & 9 & 4 & 4 & 0 & 0 \\
\hline BR & 6 & 6 & 9 & & 0 & 9 & 4 & 0 & 0 \\
\hline BTD & 6 & 6 & 9 & 0 & & 0 & 9 & 0 & 0 \\
\hline BX & 6 & 4 & 4 & 9 & 0 & & 0 & 0 & 0 \\
\hline TC & 6 & 4 & 4 & 4 & 9 & 0 & & 0 & 0 \\
\hline BAS & 0 & 0 & 0 & 0 & 0 & 0 & 0 & & 9 \\
\hline HTN & 0 & 0 & 0 & 0 & 0 & 0 & 0 & 9 & \\
\hline
\end{tabular}


Combine details into modules: use Cluster Identification Algorithm CIA identification algorithm to cluster details. Details in the product are shown in the table below:

Table 10. Product details.

\begin{tabular}{|c|l|c|c|}
\hline No & Clusters denomination & Design for selection & Design for manufactering \\
\hline 1 & Servo DC motor & $\checkmark$ & \\
\hline 2 & Coupling & $\checkmark$ & \\
\hline 3 & Reductive gearbox & $\checkmark$ & \\
\hline 4 & Belt transmission & $\checkmark$ & $\checkmark$ \\
\hline 5 & Gears & & $\checkmark$ \\
\hline 6 & Wheels & $\checkmark$ & \\
\hline 7 & Brush shaft & $\checkmark$ & $\checkmark$ \\
\hline 8 & Roller bearings & & \\
\hline 9 & Pressure pump & & \\
\hline 10 & Machine frame & & \\
\hline
\end{tabular}

\section{Conclusion}

The results show that the modules of physical structure and function are suitable: Module 1: Wheel and brush drive function; Module 2: Function of water supply for cleaning process. Seven clusters are designed for selection (purchasing from market), three parts are designed for manufacturing by ourselves. Modular design improved the design efficiency, product quality and reliability, good maintainability. Solar panel cleaning module provides an economic and effective method for cleaning the solar panel.

\section{References}

1. Thời báo Ngân hàng, Triển vọng phát triển năng luợng tại Việt Nam, https://thoibaonganhang.vn/trien-vong-phat-trien-nang-luong-mat-troi-tai-viet-nam106420.html (2020)

2. Z. M. Bi, Y. T. Sherman Lang, V. Marcel, P. Orban, Development of reconfigurable machines, Int. J Adv. Manuf. Technol (2007)

3. R. Shang, Y. F. He, Z. Zhang, Study on Evaluation System Based on the Reconfigurable and Modular Design, App. Mec and Mat. (2012)

4. R. Rahul, R. Ronald, C. P. Ignasious, J. Ignatius, R. Zachariah, Design and Fabrication of a Fully Automated Solar Panel Cleaning Module with Microfiber Brush, Emerging Technologies for Sustainability (2020)

5. N. Maindad, A. Gadhave, S. Satpute, B. Nanda, Automatic Solar Panel Cleaning System, Int. Conf. on Communication and Information Processing (ICCIP-2020), Elservier (2020).

6. N. Sugiartha, I. G. N. Ardana, I. M. Sugina, I. B. G. Widiantara, I. N. Suparta, I. K. Adi, Preliminary Design And Test Of A Water Spray Solar Panel Cleaning System, iCAST-ES 2019, J. of Phys.: Conference Series (2019)

7. Nguyễn Thanh Nam, Giáo trình phương pháp thiết kế kỹ thuật, Nhà xuất bản đại học quốc gia Tp. Hồ Chí Minh (2010)

8. A. K. Kamrani, S. M. Salhied, Product design for modularity, Second edition (2002) 